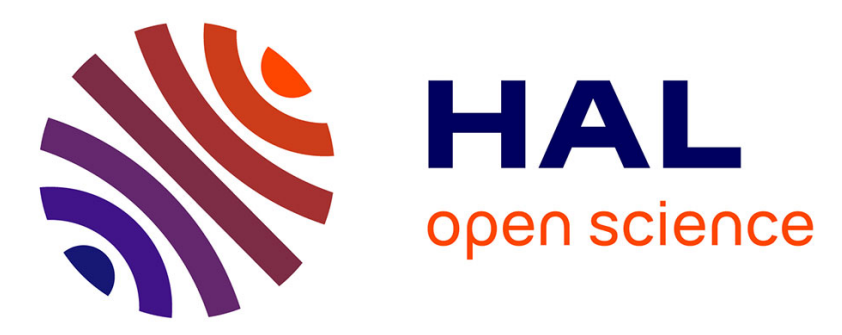

\title{
Elemental and spectroscopic characterization of humic acids fractionated by gel permeation chromatography
}

Aaziz Ouatmane, Valeria Dorazio, Mohamed Hafidi, Jean-Claude Revel, Nicola Senesi

\section{- To cite this version:}

Aaziz Ouatmane, Valeria Dorazio, Mohamed Hafidi, Jean-Claude Revel, Nicola Senesi. Elemental and spectroscopic characterization of humic acids fractionated by gel permeation chromatography. Agronomie, 2000, 20 (5), pp.491-504. 10.1051/agro:2000144 . hal-00886059

\section{HAL Id: hal-00886059 \\ https://hal.science/hal-00886059}

Submitted on 1 Jan 2000

HAL is a multi-disciplinary open access archive for the deposit and dissemination of scientific research documents, whether they are published or not. The documents may come from teaching and research institutions in France or abroad, or from public or private research centers.
L'archive ouverte pluridisciplinaire HAL, est destinée au dépôt et à la diffusion de documents scientifiques de niveau recherche, publiés ou non, émanant des établissements d'enseignement et de recherche français ou étrangers, des laboratoires publics ou privés. 


\title{
Elemental and spectroscopic characterization of humic acids fractionated by gel permeation chromatography
}

\author{
Aaziz OuAtmane ${ }^{\text {a*, }}$ Valeria DoRAZIO ${ }^{\mathrm{b}}$, Mohamed HAFIDI ${ }^{\mathrm{c}}$, Jean-Claude REVEL ${ }^{\mathrm{d}}$, \\ Nicola SENESI ${ }^{\mathrm{b}}$ \\ ${ }^{a}$ Faculté des Sciences et Techniques, Laboratoire Sol et Environnement, BP 523, Beni-Mellal, Morocco \\ ${ }^{\mathrm{b}}$ University Degli Studi, Inst. Chem. Agraria, Via Amendola 165/A, 70126 Bari, Italy \\ ${ }^{\mathrm{c}}$ Faculté des Sciences Semlalia, BP S15, Marrakech, Morocco \\ d École. Nationale Supérieure d'Agronomie, Auzeville-Tolosane, BP 107, Toulouse, France
}

(Received 21 September 1999; revised 1 February 2000; accepted 24 February 2000)

\begin{abstract}
Humic acids were extracted from one year aged farmyard manure and domestic waste composts and from carob tree fresh litter. Their elution pattern and particle weight distribution were investigated by successive gel chromatography using three grades of sephadex gel: G25, G75 and G100. The fractions obtained were characterized by elemental analysis, E4/E6 ratio, Fourier transform infrared and fluorescence spectroscopy. Compounds apparently of high molecular weight dominated in composted farmyard manure and domestic waste, nitrogen-rich, humic acids, whereas the compounds of apparently medium molecular weight were more important in the litter's, less nitrogen-rich, humic acids. Besides, the increase in molecular weight was accompanied by an important increase in the amount of nitrogenrich components and, to a lesser extent, polysaccharides and aliphatic long-chain components. Polycondensation of humic substances did not develop significantly with increasing particle weight but the confrontation of all the results agrees with the coexistence of both more or less highly humified and non-humified compounds in the large particle weight fraction. At the same time a striking similarity in either elution patterns, quantitative and qualitative composition was observed among all the fractions of the same humic acid. The structure of humic acids is discussed on the basis of these results.
\end{abstract}

\section{humic acids / gel chromatography / particle weight distribution / elemental analysis / spectroscopic} characterization

Résumé - Composition élémentaire et caractérisation spectroscopique d'acides humiques fractionnés par gel-filtration. Les acides humiques ont été extraits d'une litière de caroubier et de deux composts: un fumier de ferme et les ordures ménagères, compostés pendant un an. Les profils d'élution et la distribution des poids particulaires de ces acides

Communicated by Isabelle Lamy

* Correspondence and reprints

ouatmane @fstbm.ac.ma 
humiques ont été examinés par gel-filtration, après élutions successives sur Sephadex G25, G75 et G100. Les fractions obtenues ont été caractérisées par l'analyse élémentaire, le rapport E4/E6, l'infrarouge (transformation de Fourier) et la fluorescence. Les composés de poids moléculaire apparemment élevé dominent dans le cas des acides humiques riches en azote (fumier et ordures ménagères), tandis que les composés de poids moléculaire apparemment moyen dominent dans le cas des acides humiques plutôt pauvres en azote (cas de la litière de caroubier). De plus, l'augmentation du poids moléculaire a été accompagnée d'un net enrichissement en constituants azotés, et à moindre degré, en polysaccharides et en carbone aliphatique. Parallèlement à l'augmentation des poids moléculaires il ne semble pas y avoir de forte polycondensation des molécules humiques. Toutefois, la confrontation de l'ensemble de nos résultats est en accord avec la coexistence, dans la fraction des grosses molécules, de composés peu ou non humifiés et de composés à degré élevé d'humification. De même, il a été constaté une ressemblance entre les différentes fractions du même acide humique aussi bien à l'élution qu'à l'échelle quantitative que qualitative. La structure des acides humiques a été discutée à la lumière de ces résultats.

acide humique / gel-filtration / distribution de poids particulaire / analyse élémentaire / caractérisation spectroscopique

\section{Introduction}

Active soil humic matter has usually been divided into fulvic and humic acids based on solubility and insolubility in mineral acids, respectively. Furthermore humic acids are usually defined as humic substances of high molecular weight and high chemical heterogeneity compared to fulvic acids as reported earlier [11, 19]. The structure of humic acids is however still ill-defined and it is suggested that humic acids consist of a heterogeneous association of molecules or small humic sub-units of different chemical nature and origin $[14,17,18$, 28]. The molecular weight of humic acids would depend on the importance of such association and is supposed to vary from as low as $\sim 2000$ to perhaps 300000 Da.

The study of molecular size distribution and the characterization of the resulting particle weight fractions could be useful to understand both the chemical nature of humic acids and their effect on soil fertility. Difference in the chemical composition and total acidity between high and low molecular weight fractions were earlier reported for fulvic acids [20]. Metal binding capacity of humic substances was also found to be dependent to a large extent on their molecular weight being generally high for the fraction with low molecular weight [12]. On the other hand, in an extensive study of different soil humic acids and their fractions, it was reported that the proportion of the large particle weight fraction decreased with the progress of humification [26]. The latter authors also reported that the major components of the large particle weight fraction were proteins, polysaccharides and moities containing aliphatic long-chain as revealed by infrared spectroscopy. Thus the different particle weight fractions of a given humic acids are not necessary of the same composition. Similar finding were also reported for sludge humic acids [1].

There is still a great ambiguity about the structure and the nature of both the low, the medium and the high molecular weight fractions of humic substances. In general, the wide discrepancies reported in the literature could be related to great variation among humic substances and to the complexity of the fractionation process. The most extensively used method for such fractionation is by far gel filtration chromatography in which the separation of humic acids is based on molecular size. Disadvantages related to this method are essentially the lack of usable molecular weight standards $[4,6]$ and the inevitable interaction between humic substances and the gels [24]. Difficulty in successful fractionation could be also related to the structural sensitivity of humic substances to the nature of the extracting reagent as well as to the $\mathrm{pH}$, the ionic strength and the concentration of the extracted humic acids [2, 5, 14, 27].

In this contribution, humic acids of some rarely studied organic matter were fractionated by gel 
chromatography and characterized in relation to particle weight, using a combination of chemical and spectroscopic (UV-Visible, FT-IR and fluorescence) methods. An improvement of the knowledge of the structure of humic substances was attempted.

\section{Materials and methods}

\subsection{Extraction of humic acids}

One-year-old farmyard manure $(\mathrm{C} / \mathrm{N}=11.5)$ and domestic waste $(\mathrm{C} / \mathrm{N}=6.8)$ composts and a natural fresh litter of carob tree $(\mathrm{C} / \mathrm{N}=18)$ were used as a source of humic acids which are noted HAFm, HADu and HACar, respectively.

For the preparation of humic acids (HA), five samples of about $5 \mathrm{~g}$ were extracted with $200 \mathrm{ml}$ of $\mathrm{KOH} 0.1 \mathrm{~N}$ at room temperature for 2 hours. The extracts were separated by centrifugation at $15000 \mathrm{tmp}$ for $30 \mathrm{~min}$ and then acidified by $\mathrm{HCl}$ to $\mathrm{pH}$ 1. After 24 hours, the precipitated humic acids were recovered by centrifugation, dissolved in a small volume of $\mathrm{KOH} 0.1 \mathrm{~N}$ and again precipitated at $\mathrm{pH} 1$. This precipitation-dissolution was repeated three fold to eliminate fulvic acids. Then the five samples of each humic acid were combined and purified by repeated dialysis against distilled water using a Spectra port 2000 Da membrane to a final electrical conductivity less than $10 \mu$ s. Thereafter about $80 \mathrm{ml}$ of the unfractionated humic acid was stored at $-4{ }^{\circ} \mathrm{C}$ until analysis and the remaining solutions were fractionated by gel sephadex chromatography.

\subsection{Gel fractionation}

A column burette of $250 \mathrm{ml}$ capacity was used with a small amount of glass wool at the bottom to retain the gels. Three columns, one for each humic acid were filled with sephadex G25 and the void volume was first determined using bleu dextran and distilled water as the eluant. Samples of bleu dextrane were progressively eluted by distilled water which was added by a Pasteur pipette to a level of
$10 \mathrm{~cm}$ from the surface of the gel and then maintained at this level by an adjustable dropper of 11 capacity. The elution was hence done only by gravity and the absorbance was measured at $290 \mathrm{~nm}$ for fractions collected at $3 \mathrm{~min}$ intervals (about $2 \mathrm{ml}$ ). For humic acids, volumes of about $8 \mathrm{ml}$ were applied on the gel and eluted by distilled. The excluded fraction, eluted at the void volume, was separated from the retained fraction that diffused instead through the gel. No attention was given to the small secondary peaks inside the retained fraction. The elution was repeated enough times to fractionate the whole solution of each humic acid. The retained fractions of the same humic acid were combined and acidified to $\mathrm{pH} 1$ then the humic acid was recovered, after centrifugation, in a small volume of $\mathrm{KOH} 0.1 \mathrm{~N}$ (concentration) and then dialyzed and stored as described above. The excluded fractions were treated in a similar way and then eluted through the sephadex G75 under the same conditions as for $\mathrm{G} 25$. This procedure was repeated on G100. At the end each humic acid was separated into the fractions retained on $\mathrm{G} 25, \mathrm{G} 75$ and G100 and the fraction excluded on G100 (G > 100). For litter humic acid the excluded and the retained fractions on G100 were very close to one another and were collected together; the corresponding fraction is noted G100. In all cases the unfractionated humic acids is noted G0.

\subsection{Elemental and spectroscopic analyses}

Both the initial solution of a given humic acid and its fractions were dialyzed to a final electrical conductivity which remained less than $10 \mu$ s for more than $24 \mathrm{~h}$ and then lyophilized. Humic acid moisture was determined by heating lyophilized samples at $105^{\circ} \mathrm{C}$ for $24 \mathrm{~h}$ then the ash content was determined by burning samples (about 20 to $25 \mathrm{mg}$ ) at $550{ }^{\circ} \mathrm{C}$ overnight. Elemental analysis $(\mathrm{C}, \mathrm{H}, \mathrm{N}, \mathrm{S})$ was performed on a Fison EA 1108 CHN. Each fraction was analyzed in triplicate and the data were recorded by the EAGER 200 software. The ratio between the absorbence at wavelengths of 465 and $665 \mathrm{~nm}(\mathrm{E} 4 / \mathrm{E} 6)$ was determined in $0.05 \mathrm{~N}$ $\mathrm{NaHCO}_{3}$ on diluted $(2 \mathrm{mg} / 25 \mathrm{ml}) \mathrm{HA}$ solution. FTIR spectra were performed on $\mathrm{KBr}$ pellet using 
Nicolet 5 PC FTIR spectrophotometer with the Omnic software. Pellets were obtained by accurately weighing $2 \mathrm{mg}$ of dried HA and $300 \mathrm{mg}$ of dried $\mathrm{KBr}$ and pressing the mixture under vacuum at 10 tons for $10 \mathrm{~min}$. Fluorescence spectra were obtained on water solution of HA at a concentration of $100 \mathrm{mg} / \mathrm{l}$ after overnight equilibration at room temperature and adjustment to $\mathrm{pH} 10$ with diluted $\mathrm{NaOH}$. A Perkin-Elmer LS-5 luminescence spectrophotometer equipped with a Perkin-Elmer Data Station 3600 for data generation and processing by PECLS programs, was used for recording spectra. Emission spectra were recorded over the $380-550 \mathrm{~nm}$ range at excitation wavelength of $360 \mathrm{~nm}$. Excitation spectra were recorded over the $300-500 \mathrm{~nm}$ range at a fixed wavelength of $520 \mathrm{~nm}$. Synchronous-scan excitation spectra were measured by scanning simultaneously both the excitation, varied from 290 to $550 \mathrm{~nm}$, and emission wavelength while maintaining a constant optimized wavelength $\Delta \lambda=\lambda_{\mathrm{em}}-\lambda_{\mathrm{exc}}=18 \mathrm{~nm}$.

\section{Results}

\subsection{Gel permeation patterns}

Successive elution patterns of the three humic acids on sephadex G25, G75 and G100 are shown in Figure 1. Each chromatogram could be divided into two main parts: I and II. I corresponds to the excluded fraction as it was eluted at the same volume as bleu dextran. II was always eluted at higher volume and corresponds to the retained fraction.

Based on this separation the chromatogram on G75 was obtained by the elution of fraction I excluded on G25 and that on G100 was the result of the elution of the excluded fraction on G75. The separation of the two main fractions, I and II, was more or less evident from the chromatograms but it was well distinguished and highly visible on the gels. In fact the separation of all humic acids appears from the first $\mathrm{cm}$ of the column and as the elution proceeds the first fraction remained concentrated giving a true peak while the second fraction diffused throughout the gel in a way that no peak could be recorded. On the other hand it appears that all chromatograms ended with a very small peak (fraction III) which was ubiquitous regardless of the type of humic acid, the particle weight fraction and the gel used. The amount of this fraction was reduced to a minimum by dialyzing both the initial solution and the excluded fraction as this was confirmed in a preliminary separation. At the end of this successive gel permeation each HA was separated into the following fractions: G25, G75, G100 and/or $\mathrm{G}>100$.

\subsection{Particle weight distribution, elemental composition and E4/E6 ratios}

The particle weight distributions of humic acids are shown in Figure 2. The distribution obtained was similar for HA Fm and HA Du being dominated by the large particle fractions (G100 and G > 100 ) followed by the middle one (G75). The opposite was obtained for litter HA.

Elemental composition and the E4/E6 ratios are given in Table I. Compared to litter HA those obtained from composted farmyard manure and domestic wastes exhibited higher nitrogen contents and lower $\mathrm{C} / \mathrm{N}$ ratios. With increasing particle weight fraction the most important change was an increase in the nitrogen content and a decrease in the $\mathrm{C} / \mathrm{N}$ ratio and this was observed for the three humic acids. Both carbon, hydrogen and oxygen content were relatively constant regardless of the particle weight of the fractions. The exception to this was observed for the largest particle fraction ( $\mathrm{G}>100)$ of HAFm and HADu which showed high carbon content and low oxygen content for HAFm and exactly the opposite for AHDu.

The E4/E6 ratio is relatively high for humic acids extracted from composted domestic waste and manure compared to litter humic acid. However similar trends are observed and this ratio decreased gradually with an increase in particle weight fraction. The most significant decrease was obtained in the case of litter humic acid. 

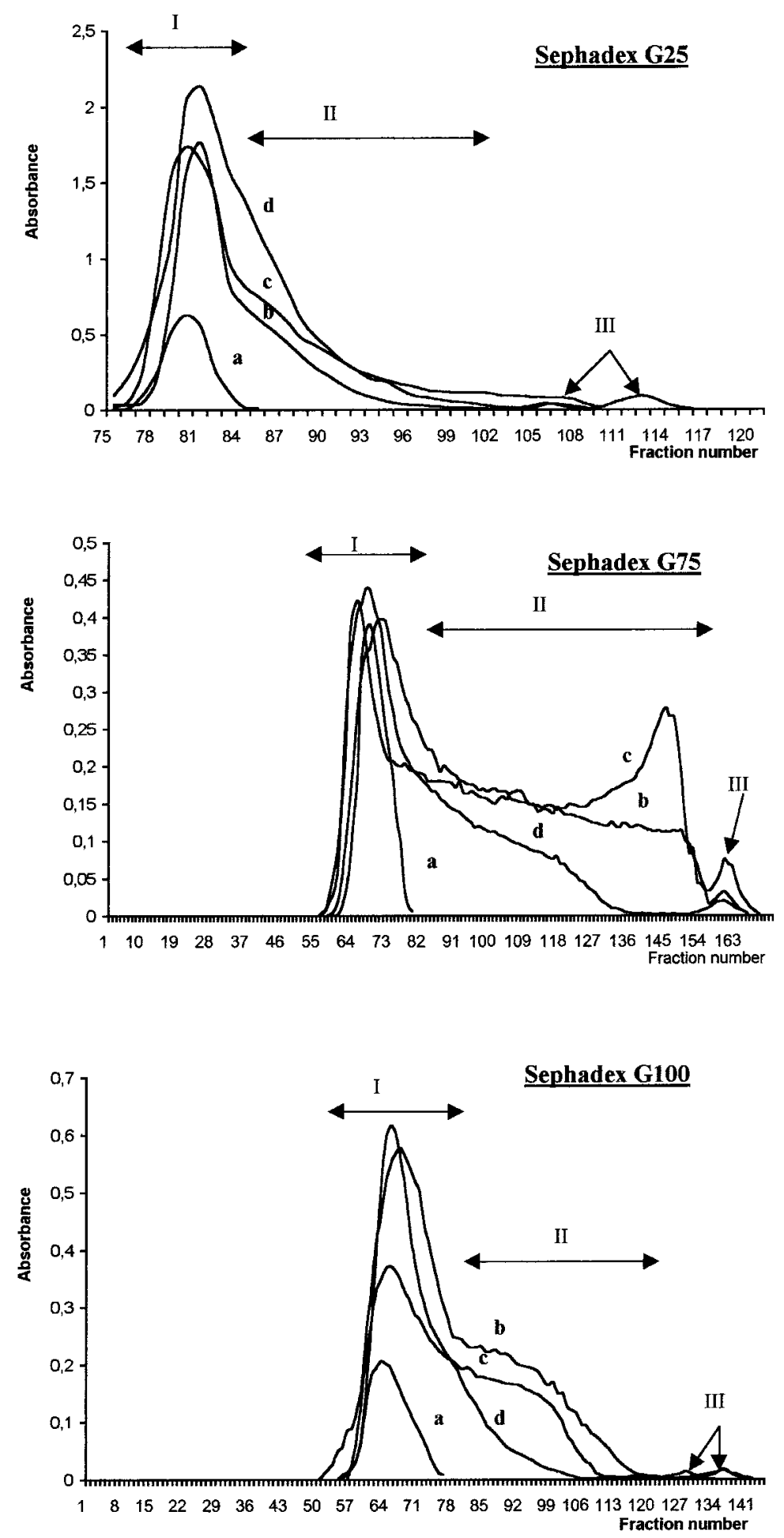

Figure 1. Successive gel permeation patterns of composted domestic waste (b) and farmyard manure (c) humic acids and of litter humic acid (d) on sephadex gel G25, G75 and G100. Bleu dextrane chromatograms (a). 


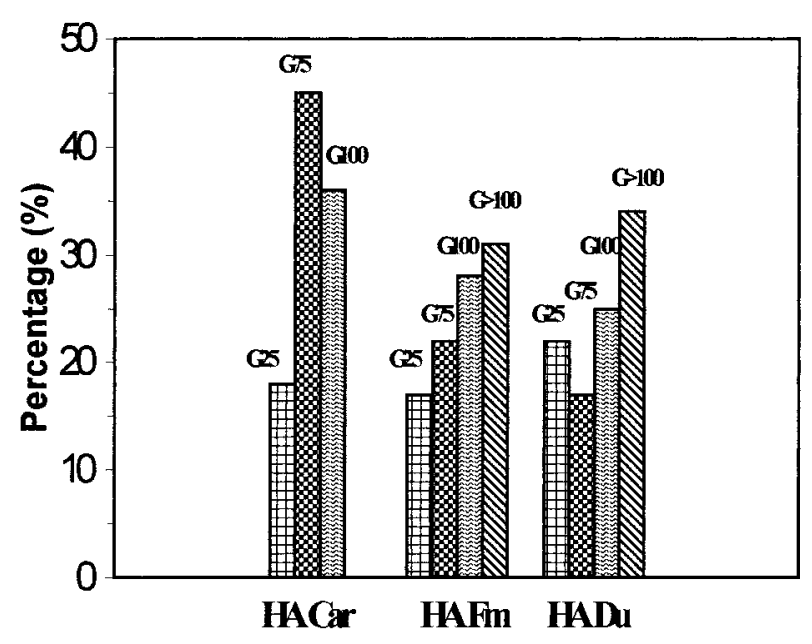

Figure 2. Particle weight distribution of humic acids of composted farmyard manure (HA Fm) and domestic waste (HA $\mathrm{Du}$ ) and of litter (HA Car). Distribution is expressed as percentage of the total weight for each sample of humic acids.

\subsection{FTIR spectra}

The IR spectra of the three humic acids and theirs fractions are shown in Figure 3. Interpretation of the spectra was based on the following literature: Schnitzer and Khan [19], Bellamy [3]; Stevenson [23] and Durig et al. [7].

General comparison between spectra pointed out similar IR features regardless of the nature of the humic acids and their particle weight. Major and common recorded bands were: a broad band around $3400 \mathrm{~cm}^{-1}$ (H- bonded $\mathrm{OH}$ groups), a sharp peak at $2925 \mathrm{~cm}^{-1}$ (aliphatic C-H stretch), a well pronounced broad peak at $1600 \mathrm{~cm}^{-1}$ (aromatic $\mathrm{C}=\mathrm{C}$, $\mathrm{C}=\mathrm{O}$ and $/$ or $\mathrm{C}=\mathrm{O}$ of bonded conjugated ketones, quinone, $\mathrm{C}=\mathrm{O}$ stretch of amide $\mathrm{I}$ ) a broad band at $1387-1400 \mathrm{~cm}^{-1}\left(\mathrm{COO}-, \mathrm{CH}_{3}\right)$, a peak at $1275 \mathrm{~cm}^{-1}$ (C-O stretching of aryl ethers), a shoulder peak at $1125 \mathrm{~cm}^{-1}$ (aromatic ring bends, symmetric bending of aliphatic $\mathrm{CH}_{2}, \mathrm{OH}$ or $\mathrm{C}-\mathrm{O}$ stretch of various

Table I. Elemental composition and E4/E6 ratio of composted farmyard manure (AHFm) and domestic waste (AHDu) humic acids, litter (AH Car) humic acids and their fractions.

\begin{tabular}{|c|c|c|c|c|c|c|c|c|c|c|c|}
\hline \multirow{2}{*}{$\begin{array}{l}\text { Humic acid } \\
\text { sample }\end{array}$} & \multirow{2}{*}{$\begin{array}{l}\mathrm{ls} \\
\mathrm{Hu}\end{array}$} & \multirow[b]{2}{*}{ Ash } & \multirow[b]{2}{*}{$\mathrm{C}$} & \multirow[b]{2}{*}{$\begin{array}{l}\mathrm{H} \\
(\%)\end{array}$} & \multirow[b]{2}{*}{$\mathrm{N}$} & \multirow[b]{2}{*}{$\mathrm{O}$} & \multirow[b]{2}{*}{$\mathrm{S}$} & \multicolumn{3}{|c|}{ Atomic ratio } & \multirow[b]{2}{*}{ E4/E6 } \\
\hline & & & & & & & & $\mathrm{C} / \mathrm{N}$ & $\mathrm{C} / \mathrm{H}$ & $\mathrm{C} / \mathrm{O}$ & \\
\hline \multicolumn{12}{|l|}{ HACar } \\
\hline G-0 & 7.0 & 6.9 & 37.2 & 4.5 & 1.9 & 42.1 & 0.18 & 22.2 & 0.7 & 1.2 & 3.8 \\
\hline G-25 & 6.8 & 4.2 & 41.1 & 4.5 & 1.6 & 40.9 & 0.86 & 29.9 & 0.7 & 1.3 & 5.6 \\
\hline G-75 & 7.2 & 6.2 & 37.8 & 4.1 & 2.2 & 42.6 & $=$ & 20.3 & 0.8 & 1.2 & 3.1 \\
\hline G-100 & 6.6 & 5.6 & 38.4 & 4.4 & 2.4 & 42.8 & $=$ & 18.4 & 0.7 & 1.2 & 2.0 \\
\hline \multicolumn{12}{|l|}{ HAFm } \\
\hline G-0 & 5.2 & 5.6 & 44.1 & 4.7 & 3.4 & 36.8 & 0.15 & 15.0 & 0.8 & 1.6 & 4.8 \\
\hline G-25 & 6.1 & 4.0 & 40.5 & 4.4 & 2.5 & 42.6 & $=$ & 19.1 & 0.8 & 1.3 & 5.1 \\
\hline G-75 & 6.8 & 5.1 & 40.0 & 4.5 & 3.2 & 40.4 & $=$ & 14.8 & 0.7 & 1.3 & 4.9 \\
\hline G-100 & 5.1 & 6.1 & 42.5 & 4.4 & 3.6 & 38.1 & 0.18 & 13.8 & 0.8 & 1.5 & 4.4 \\
\hline$G>100$ & 5.5 & 5.8 & 58.1 & 6.4 & 4.8 & 19.4 & $=$ & 14.3 & 0.7 & 4.0 & 4.1 \\
\hline \multicolumn{12}{|l|}{ HADu } \\
\hline G-0 & 5.2 & 6.7 & 36.6 & 3.8 & 4.4 & 43.2 & $=$ & 9.7 & 0.8 & 1.1 & 5.9 \\
\hline G-25 & 6.1 & 5.0 & 35.8 & 3.6 & 2.7 & 46.8 & $=$ & 15.0 & 0.8 & 1.0 & 6.2 \\
\hline G-75 & 7.0 & 5.9 & 37.2 & 3.8 & 3.5 & 42.6 & $=$ & 12.2 & 0.8 & 1.2 & 5.8 \\
\hline G-100 & 6.7 & 6.4 & 35.2 & 3.9 & 5.2 & 42.7 & $=$ & 7.9 & 0.7 & 1.1 & 5.8 \\
\hline$G>100$ & 5.3 & 6.6 & 19.6 & 5.0 & 5.3 & 58.4 & $=$ & 4.3 & 0.3 & 0.4 & 5.1 \\
\hline
\end{tabular}




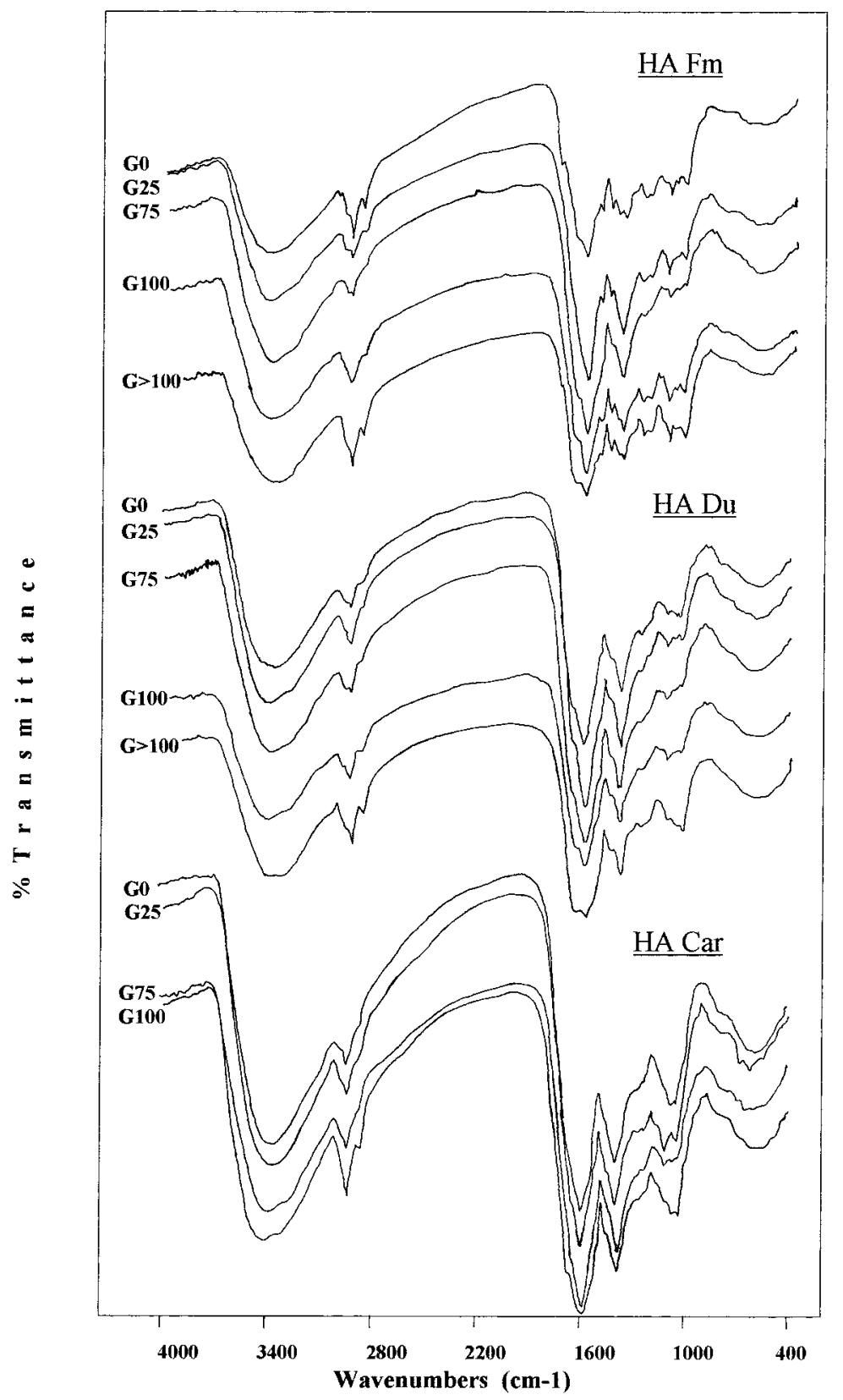

Figure 3. FTIR spectra of the unfractionated (G0) and the fractions G25, G75, G100 and G > 100 of composted farmyard manure (HA Fm) and domestic waste (HA Du) humic acids and of litter humic acids (HA Car). groups) and a peak at $1044 \mathrm{~cm}^{-1}(\mathrm{C}-\mathrm{O}$ stretch of polysaccharides or polysaccharides-like substances, $\mathrm{Si}-\mathrm{O}$ of silicates). Furthermore, litter HA gives more or less simpler IR spectra which were reduced to the major band cited above, while the two other HA exhibit spectra with many additional secondary peaks.
By analyzing spectra of each fraction for a given HA it appears that with increasing particle weight fraction there was a clear gradual increase in the intensity of the absorption at $1650 \mathrm{~cm}^{-1}$ (hydrogen bonded, $\mathrm{C}=\mathrm{O}$ stretch, amide I) giving a new peak in the $\mathrm{G}>100$ fraction mostly for HAFm and HADu 


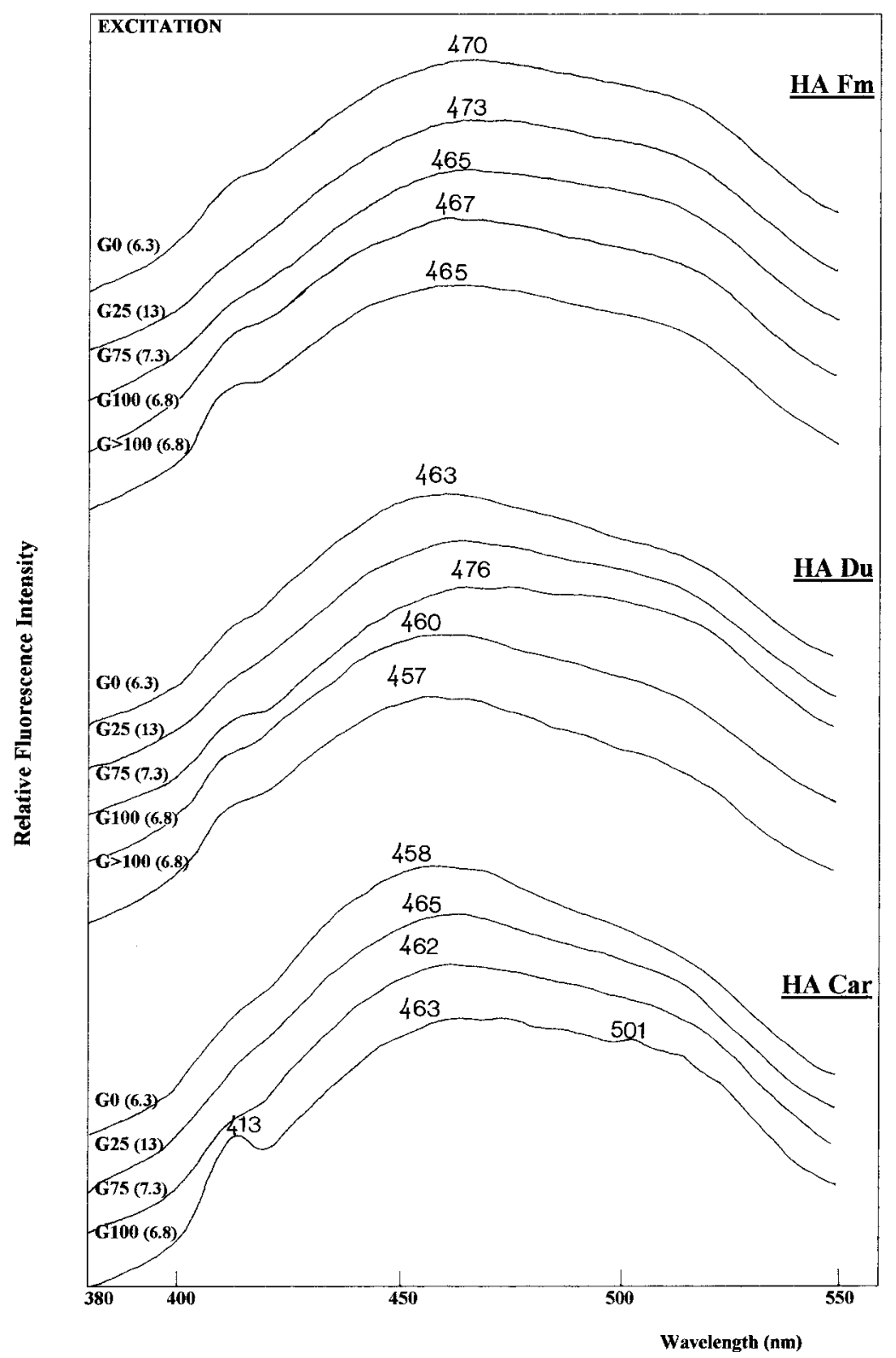

Figure 4. Fluorescence excitation spectra of the unfractionated (G0) and the fractions G25, G75, G100 and $\mathrm{G}>100$ of composted farmyard manure (HA Fm) and domestic waste (HA Du) humic acids and of litter humic acids (HA Car).

humic acids. There was also a little but common increase in the intensity of the two peaks $2925 \mathrm{~cm}^{-1}$ and $1040 \mathrm{~cm}^{-1}$ essentially in the large particle fraction $(G>100)$.

\subsection{Fluorescence spectra}

The fluorescence in emission, excitation and synchronous-scan excitation of humic acids is shown in Figures 4, 5 and 6 respectively. Emission spectra of humic acids and their fractions show a unique broad band with a maximum within a limited range: 457-476 nm (Fig. 4). With increasing particle weight fraction no apparent change was observed for litter HA while there was a very small shift of the emission maximum to lower wavelength for the two other humic acids. The relative fluorescence intensity (RFI) measured on the emission 


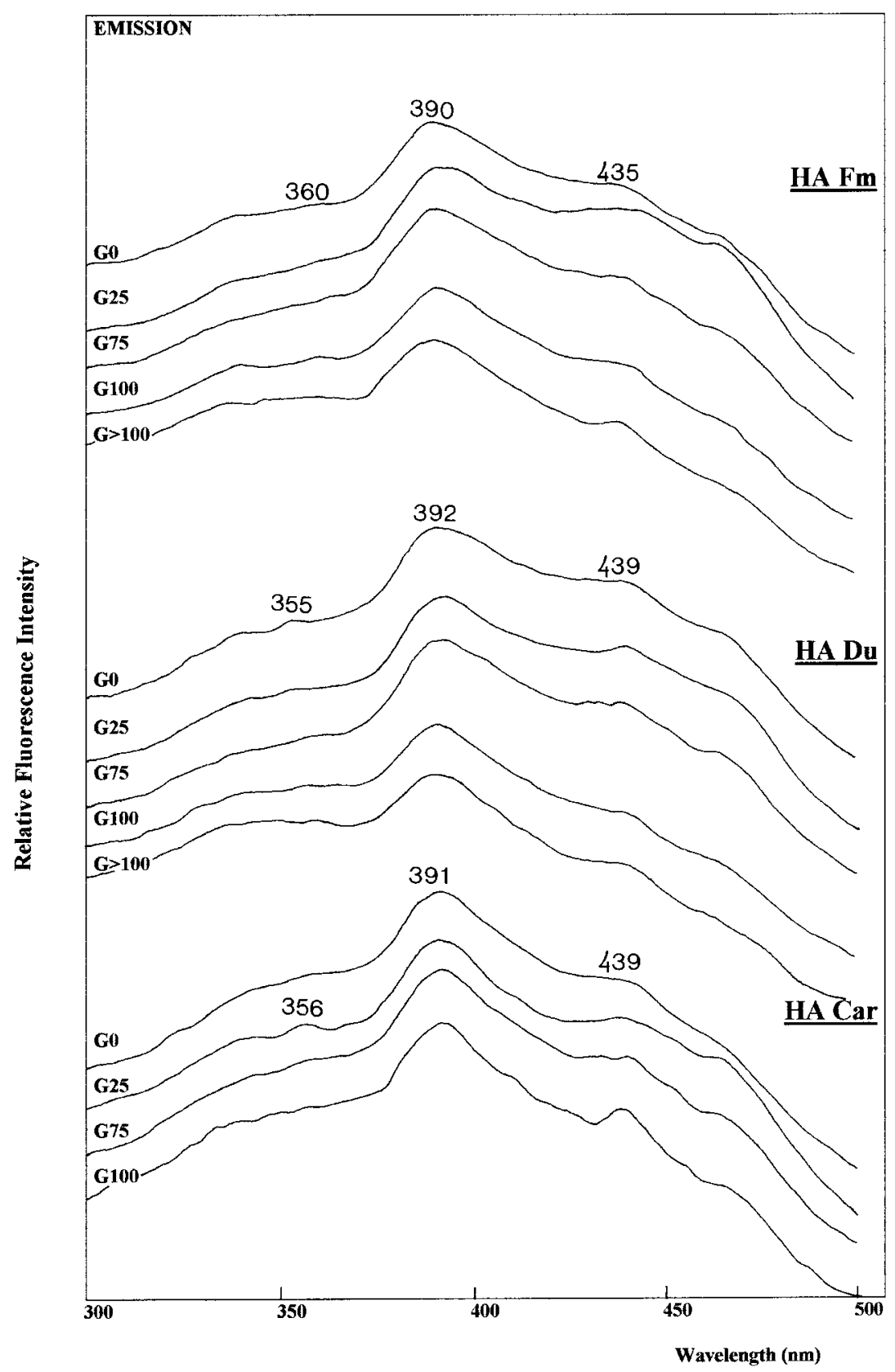

Figure 5. Fluorescence emission spectra of the unfractionated (G0) and the fractions G25, G75, G100 and $\mathrm{G}>100$ of composted farmyard manure (HA Fm) and domestic waste (HA Du) humic acids and of litter humic acids (HA Car). Values of the relative fluorescence intensity are given within brackets.

spectra varied from 6.3 to 9.4 for the unfractionated humic acids and showed an important and gradual decrease from fraction $\mathrm{G} 25$ to $\mathrm{G}>100$ in case of litter HA. For AHDu and $\mathrm{AH}$ Fm an important decrease was observed from G25 to G75 but no further decrease of RFI was obtained for G100 and $\mathrm{G}>100$. Fluorescence excitation spectra of humic acids and their fractions were close to each other showing one main peak around $390 \mathrm{~nm}$ with one or two additional excitation peaks or shoulders at lower and longer wavelengths. No apparent change in fluorescence excitation was observed among the different particle weight fractions. Synchronousscan excitation spectra were however more or less typical for each humic acid. The main peak was recorded at 468, 473 and $455 \mathrm{~nm}$ for unfractionated 


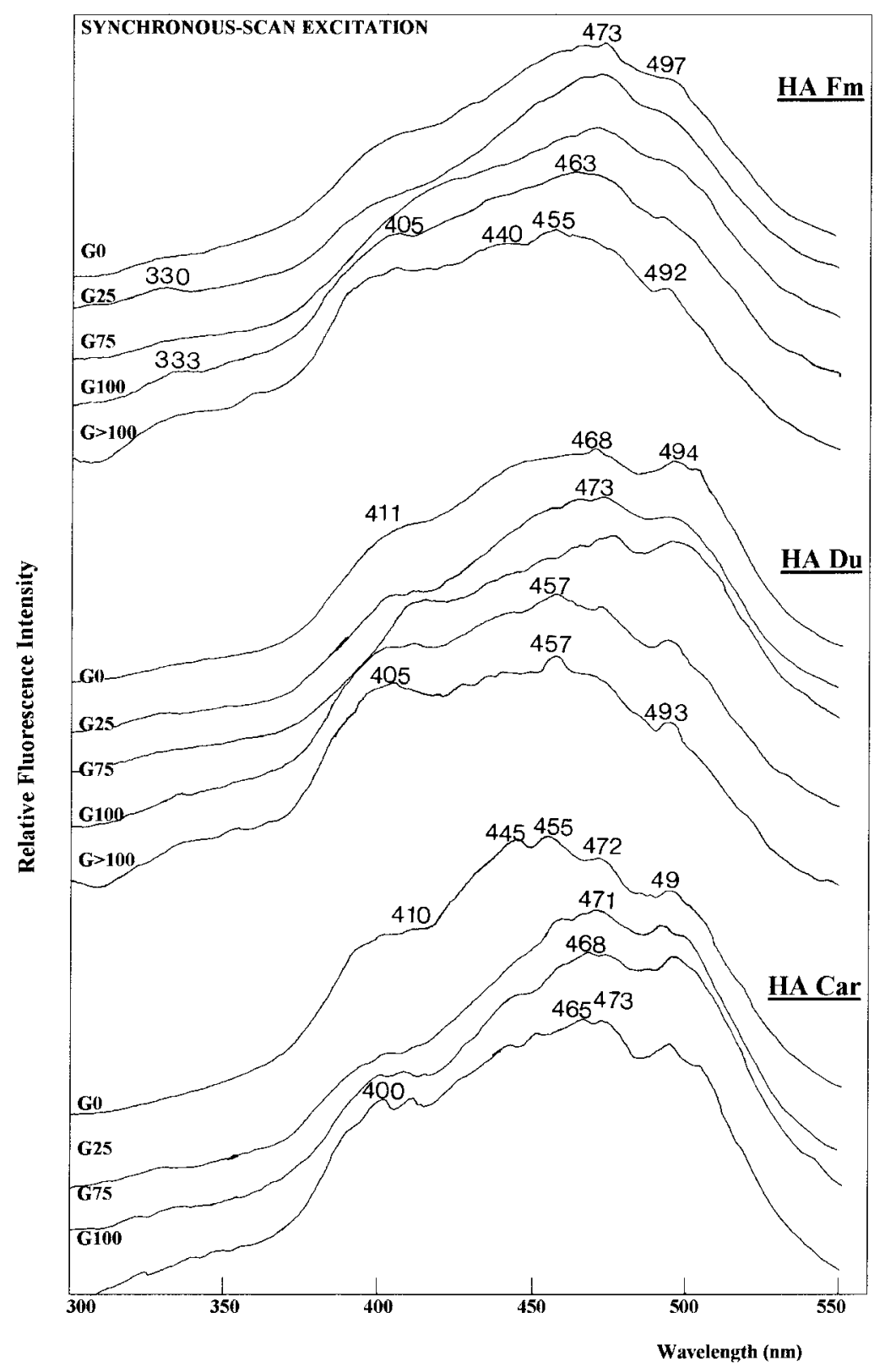

Figure 6. Synchronous-scan excitation spectra of the unfractionated (G0) and the fractions G25, G75, G100 and $\mathrm{G}>100$ of composted farmyard manure (HA Fm) and domestic waste (HA Du) humic acids and of litter humic acids (HA Car).

humic acids of domestic wastes, farmyard manure and fresh litter respectively. The secondary peaks at 400-410 nm and $494 \mathrm{~nm}$ were observed on all spectra. Furthermore a great similarity was observed among the small fractions (G-25) giving the main peak at 471-473 nm. With increasing particle weight fraction the most important change was a decrease in RFI resulting in flattened spectra and the appareance of new peaks at low wavelength mostly the peak at $457 \mathrm{~nm}$ which was also the main one in the large particle weight fraction of AHDu. At the same time the peaks at $471-473 \mathrm{~nm}$ did not disappear but they became of secondary importance. 


\section{Discussion}

Humic acids can be separated into distinct fractions based on their molecular weight and/or conformational arrangement state as previously reported by numerous works where gel permeation chromatography was the most used approach. Generally molecular weight estimation is avoided due to the lack of appropriate standards for the calibration of the gel. Thus, the fractionation of humic acids was always limited to their separation into distinct categories of molecules or molecular family by using different gels with different size exclusion limit $[2,5,16,26]$. The same technique was used here and applied for the study of humic acids from fresh litter and from composted farmyard manure and domestic waste. The successive elutions on sephadex G-25, G-75 and G-100 showed more or less the same profile: an excluded fraction (I) followed by a retained fraction (II) which diffused throughout the gels and a small and well retarded like-fraction (III) at the end of each chromatogram. This elution pattern was reproducible irrespective of the gel and the type of humic acid. These findings are similar to those reported for soil humic acids by other authors $[2,25]$. The retained fraction was not an adsorbed part of the excluded one but a well individualized fraction even if the separation of the two fractions was experimentally not very accurate. The closeness of these two fractions (I and II) on both G25, G75 and G100 is however a proof that the molecular weight gradient is continuous from the small to the large humic macromolecules.

The retarded fraction (III) showed elution characteristics which could not be related to a given molecular weight due mainly to its slow and abnormal progression throughout the gel and to its ubiquitous character. According to Blondeau [5], this fraction corresponds to the fraction with the smallest molecular weight for a given gel and it results from the formation of insoluble humate-sodium complexes. Besides, the amount of this fraction was found to be proportional to sodium ion concentration in a way that it gives a misleading peak with increasing $\mathrm{NaOH}$ concentration. It was reported also that this fraction has the same elution volume as sodium ion and behaves as adsorbed sodium humate complexes but no indication could be given about its molecular weight as well as about its nature [2]. In our case insoluble potassium humates could be formed. It must however be noted that during the present study the reproducibility of the fractionation was excellent and the distinction between the excluded and retained fraction was always clear. Although adsorption effects could not be overcome as revealed by the retarded fraction, no irreversible adsorption was observed even after prolonged use of the gels, based on visual observation.

Particle weight distribution of obtained fractions showed the predominance of the high molecular weigh fraction for composted farmyard manure and domestic waste while the medium one dominated in litter humic acids. Similar predominance of the high molecular weight fraction was reported for sludge humic acids and it was attributed to the possible presence of high amounts of large-sized and low-condensed lignin-like constituents bearing peripheral lipidic and/or peptidic chains $[1,15]$. In our case both E4/E6 and elemental analysis results agree and are in favor of such hypothesis as the increase in particle weight fraction of HAFm and HADu was accompanied by a substantial increase in nitrogen content and $\mathrm{C} / \mathrm{N}$ ratio decrease and a minor decrease of E4/E6 ratio. Such a trend in the change of these parameters agrees with an important increase in the amount of peptidic structures and a limited degree of polycondensation or humification at the same time. In fact and according to Orlov et al. [13] and Tomikawa and Oba [26] when the molecular weight of humic acids increased only due to colorless components such as proteins and polysaccharides the ratio between the absorbence at 400 and $600 \mathrm{~nm}$ remained constant. In contrast, a significant decrease of the E4/E6 ratio was recorded for the higher molecular weight fraction of soil humic acids which were dominated by highly humified or colored components [26, 27]. This could be the case for litter humic acids for which the increase in molecular weight appears to be more related to an increase in humification degree (low E4/E6) even though the involvement of proteinaceous components could not be excluded. On the other hand, both carbon, hydrogen and oxygen content and $\mathrm{C} / \mathrm{H}$ 
and $\mathrm{C} / \mathrm{O}$ ratios of these humic acids were close to each other regardless of the particle weight of the fractions. Based on this result one could suggest that the large particle weight fraction is simply an association of small precursor or humic sub-units with the same elemental composition. By employing low pressure size exclusion chromatography, direct evidence in favor of such suggestion was given by Piccolo [14] according to which humic macromolecules can be regarded as associations of humic sub-units or aggregates held together by hydrophobic forces.

Spectroscopy results, in particular infrared spectroscopy, are in a good agreement with those of both elemental and E4/E6 ratio. In fact and first, it appears that both the low, the medium and the high particle weight fraction of each humic acid have also the same qualitative composition which resulted in similar IR spectra. Secondly and based on nitrogen content results, the observed increase in the absorption intensity near $1650 \mathrm{~cm}^{-1}$ which accompagnied particle weight increase could be attributed mostly to an increase in the importance of the amide band arising from proteinaceous components. The involvement of $\mathrm{N}$-acetylamino-sugars is also possible, mainly in the case of domestic waste. With increasing particle weight fraction there was also an increase in the importance of aliphatic structures $\left(2925 \mathrm{~cm}^{-1}\right.$ peak) and polysaccharide components $\left(1040 \mathrm{~cm}^{-1}\right.$ peak) but not of silicates as there was no correspondent increase in either ash or sulfur content. In general these finding are close to those reported by Tomikawa and Oba [26] who found that all the fractions with the higher particle weight of ten soil humic acids showed absorption peaks arising from proteins, polysaccharides, aliphatic compounds, and lignin-like substances. Moreover, the absorption from these components increased gradually with increasing particle weight in most cases. According to Tsutsuki and Kuwatsuka [27], the high molecular weight fraction of humic substances contains both highly humified components and a large amount of colorless components. Our results may account for the fact that the polycondensation of aromatic compounds with increasing particle weight did not develop significantly, due probably to the relatively young nature of humic acids.
On the other hand and according to fluorescence spectroscopy the striking similarity observed between fractions of different particle weight from the same humic acid was also easy to confirm. Moreover, fluorescence in emission, excitation and synchronous excitation showed characteristics which are intermediate between those typical of soil humic acids and fulvic acids and are close to those of newly formed humic acids [22]. It is however interesting to see that the relative fluorescence intensity (RFI) decreased with increasing particle weight mostly in case of less nitrogen-rich litter humic acid. Ewald et al. [8] and Hall and Lee [9], found similar results for sephadex gel chromatographically- and the ultrafiltration-separated fractions of fulvic acids of various origins. This result was ascribed to the elevated presence of electrondonating groups, such as hydroxyl, methoxyl and amino groups on low molecular humic molecules. Although there was no experimental evidence for such hypothesis, it must be noted that the decrease in RFI appears to be limited by an increase in the amino groups contents in the nitrogen-rich large particle weight fraction of domestic waste and farmyard manure humic acids. The inverse was true for litter humic acid. Synchronous-scan spectra appeared to be typical for each HA, and were in agreement with previous results [22]. Compared to the large particle weight fraction, the small fraction provided much simpler synchronous spectra which were close to those typical for soil humic acids, with a broad band at $470 \mathrm{~nm}$. With increasing particle weight fraction a new additional peaks at a lower wavelength were recorded on nitrogen rich fractions giving spectra close to those shown by soil FA and HA of earthworm-composted organic matter $[10,21]$. With regard to previous results [22] it appears that the large particle weight fractions are closer to the class of young humic substances than the small fractions. These results are, however, not surprising but they simply translate the high heterogeneity of fluorescing groups in the large particle weight fraction and probably the coexistence of both low or non-humified and more or less highly humified or polycondensed components as constituents of humic macromolecules. Besides, the fluorescence detection of possible polycondensed 
humic structure in the large particle fraction could be masked by the abundant presence of the non humified nitrogen-rich components. We do not however know whether these latter components are really integrated in the structure of humic macromolecules or whether they represent independent components which were eluted simply according to their proper molecular weight.

\section{Conclusion}

This study reports direct evidence that humic acids can exhibit similar elution patterns irrespective of their molecular weight and origin. Besides, it appears that the molecular weight gradient is continuous from the small to the very large humic macromolecules.

From elemental and spectroscopic study it can be concluded that both the low, the medium and the large particle weight fractions of humic acids are, more or less, of the same quantitative and qualitative chemical composition. Accordingly, humic macromolecules can be regarded as associations of humic sub-units which are of the same nature. However, for the three humic acids studied, the largest particle weight fractions were the most heterogeneous ones and appear to contain both highly humified components and higher level of low- or non-humified components which are probably of proteinaceous nature. The structural relationship between these two latter components deserves further interest as it should help for a better knowledge of the structure of humic substances.

Acknowledgement: This work was financed in part by the AUPELF Project J.E.R. 6013.

\section{References}

[1] Almendros G.A., Dorado E., Estudio de la materia organica de deversos tipos de lodos residuales de la provincia de Madrid, Agrochimica 27 (1983) 439-454.

[2] Bailly J.R., Sur la structure des substances humiques et le rôle des microorganismes dans leur formation, thèse Doctorat d'État Univ. Paul Sabatier, Toulouse, France, 1985, 380 p.
[3] Bellamy, L.J., The Infrared Spectra of Complex Molecules, Chapman and Hall, 3rd ed., Vol. 1, London, 1975.

[4] Berdén M., Berggren D., Gel filtration chromatography of humic substances in soil solutions using HPLCdetermination of the molecular weight distribution, J. Soil Sci. 41 (1990) 61-72.

[5] Blondeau R., The fractionation of humic acids on sephadex gel: the role of salts and extractants, Agrochimica 30 (1986) 128-136.

[6] Cameron R.S., Thornton B.K., Swift R.S., Posner A.M., Calibration of gel permeation chromatography materials for use with humic acid, J. Soil Sci. 23 (1972) 342-349.

[7] Durig D.T., Esterle J.S., Dickson T.J., Durig J.R., An investigation of the chemical variability of woody peat by FTIR spectroscopy, Appl. Spectrosc. 42 (1988) 1239-1244.

[8] Ewald M., Berger P., Visser S.A., UV-visible absorption and fluorescence properties of fulvic acids of microbial origin as functions of their molecular weights, Geoderma 43 (1988) 11-20.

[9] Hall K.J., Lee G.F., Molecular size and spectral characterization of organic matter in a meromectic lake, Water Res. 8 (1974) 239-251.

[10] Hervas L., Mazuelos C., Senesi N., Saiz-Jimenez C., Chemical and physico-chemical characterization of vermicomposts and their humic acid fractions, Sci. Total Environ. 81, 82 (1989) 543-550.

[11] Kononova M.M., Soil Organic Matter, its Nature, its Role in Soil Formation and in Soil Fertility, Pergamon Press, UK, 1966.

[12] Kuiters A.T., Mulder W., Gel permeation chromatography and $\mathrm{Cu}$-binding of water-soluble organic substances from litter and humus layers of forest soil, Geoderma 52 (1992)1-15.

[13] Orlov D.S., Ammosova Y.M., Glebova G.I., Gorshkova Y.I., Il'in N.P, Kolesnikov M.P., Molecular weights, sizes, and configuration of humic acid particles, Sov. Soil Sci. 3 (1971) 673-687.

[14] Piccolo A., New insights on the conformational structure of humic substances as revealed by size exclusion chromatography, in: Drozd J. et al. (Eds.), The Role of Humic Substances in the Ecosystems and Environmental Protection, 8th Meeting IHSS, Poland, 1997.

[15] Piccolo A., Zacheo P., Genenini P.G., Chemical characterization of humic substances extracted from organic-waste-amended soils, Bioresource Technol. 40 (1992) 275-282. 
[16] Roletto E., Cerruti M., Barberis R., Investigation on humic matter from decomposting spruce bark, Agric. Wastes 12 (1985) 261-272.

[17] Schnitzer M., Humic substance: chemistry and reactions, in: Schnitzer M., Khan S.U. (Eds.), Soil Organic Matter, Elsevier, Amsterdam, 1978, pp. 1-64.

[18] Schnitzer M., A chemical structure of humic acid. Chemical ${ }^{13} \mathrm{C}$ NMR, Colloid chemical, and electron microscopic evidence, in: Senesi N., Miano T.M. (Eds.), Humic substances in the global environment and implications on human healt, Elsevier, Amsterdam, 1994, pp. 57-69.

[19] Schnitzer M., Khan S.U., Humic substances in the environment, Marcel Dekker, New York, 1972.

[20] Schnitzer M., Skinner I.M., in: Isotope and Radiation in Soil Organic Matter Studies, Gel Filtration of Fulvic Acid, a Soil Humic Compound, International Atomic Energy Agency, Vienna, 1968, pp. 41-55.

[21] Senesi N., Miano T.M., Provenzano M.R., Brunetti G., Spectroscopic and compositional comparative characterization of some I.H.S.S. reference and standard fulvic and humic acids of various origin, Sci.Total Environ. 81, 82 (1989) 143-156.

[22] Senesi N., Miano T.M., Provenzano M.R., Brunetti G., Characterization, differentiation, and classi- fication of humic substance by fluorescence spectroscopy, Soil Sci. 152 (1991) 259-271.

[23] Stevenson F.J., Humus chemistry: Genesis, Composition, Reactions, John Wiley, New York, 1982.

[24] Swift R.S., Posner A.M., Gel chromatography of humic acid, J. Soil Sci. 22 (1971) 237-249.

[25] Tomikawa A., Oba Y., Characteristics of soil humic substances fractioned with respect to particle weight. I. Particle weight fractionation of humic substance by successive Sephadex gel filtration, Jpn. J. Soil Sci. Plant Nutr. 55 (1984) 421-426.

[26] Tomikawa A., Oba Y., Characteristics of soil humic substances fractioned in relation to particle weight. I. Particle weight distribution; optical properties, and infrared absorption spectra of fractions of humic acids with different particle weights, Soil Sci. Plant Nutr. 37 (1991) 211-221.

[27] Tsutsuki K., Kuwatsuka S., Molecular size distribution of humic acids as affected by the ionic strength and the degree of humification, Soil Sci. Plant Nutr. 30 (1984) 151-162.

[28] Wershaw R.L., A new model for humic materials and their interactions with hydrophobic organic chemicals in soil-water or sediment-water systems, J. Contam. Hydrol. 1 (1986) 29-45. 